\title{
Quantitative Model of Collision Causes in Japan
}

\author{
Haryanti RIVAI *, Kohei HIRONO ** and Masao FURUSHO ***
}

\begin{abstract}
Sea route around Japan has high traffic density. The ratio of ship's collision is $62.6 \%$ represented from the total kind of marine accidents since 1998-2008 (Marine Accident Inquiring Agency(MAIA),Japan). Measuring for risk minimization, such as the quantitative method, which evaluated with respect to their performance relationships between man, machine, media and management, is still very rarely used. Furthermore, the development of quantitative model in a simple and sequential way would be helpful to explain and predict phenomena in the accident to the specific problems that are used. As a result the probability relationships between causes of collision in the term maritime transport systems have been estimated.
\end{abstract}

Keywords: marine casualty, causes of collision, maritime transport system, human element, quantitative model

\section{Introduction}

\subsection{Backgrounds}

Sea routes around Japan have high traffic density. The collisions of ships represented $62.6 \%$ of the total kinds of maritime accidents in the period 1998-2008 (Source: by Marine Accident Inquiring Agency (MAIA),Japan) ${ }^{[1]}$. The Japan Marine Accident Inquiry Agency (JMAIA), since October 2008 merged with the ARAIC (Air and Rail) and now known as the Japan Transport Safety Board (JTSB), is the Japanese government agency that investigates causes of accidents on ships.

According to maritime accidents statistics, the collision is one of the casualties occurring at sea. Accidents, including collisions, still occur at a high rate every year; even when competent navigators are controlling the ship. Dependence on human performance in the motion and safety of the ship is very important. Written studies ${ }^{[2,3,4]}$, of research into the maritime casualty area reveal that $96 \%$ of all collisions can be attributed to the human element.

\subsection{Objectives}

The objectives of this study are to analyze the human element as an indirect contributory cause of collisions as variable X1-X29 and to analyze the relationships between elements in the maritime transport system considering the factors of man, machine, media and management. Considerable progress has been made, and some frequently occurring unsafe acts in collisions have been roughly identified; collision risk incorporating human factors has been estimated quantitatively; navigators' customary behavior in collision avoidance has been mathematically modeled.

\section{Human Element in Collision Accidents 2.1 Human Element in Navigation Systems}

The maritime transport system is a very complex and large-scale socio-technical environment (STE) system comprising human and man-made entities that interact with each other and operate in a physical environment.

The main elements of the system are objects of transport, infrastructures and facilities, which are linked by the information system and transport-related activities $^{[5]}$. The human element is a very important element that designs, develops, builds, operates, manages, regulates and interacts with other elements

\footnotetext{
* Student Member: Graduate School of Maritime Sciences ( ̄ 658-0021) Kobe University, haryantirivai@gmail.com

** Member: Graduate School of Maritime Sciences ( $\quad$ T658-0021) Kobe University

*** Member: Graduate School of Maritime Sciences ( $\bar{\top} 658-0021$ ) Kobe University
} 
of this system. These elements are embedded in very complex, interdependent, and dynamic relationships. The IMO Assembly adopted resolution A.850(20) ${ }^{[6]}$, which interpreted the meaning of the term "human element" as "a complex multidimensional issue that affects maritime safety and marine environmental protection"; it "involves the entire spectrum of human activities performed by ship's crew, shore based management, regulatory bodies, recognized organizations, shipyards, legislators and other relevant parties". It means that the human element is a component of a system.

The navigation system is established as a maritime safety system with three subsystems: operator, ship and environment. The relationships among the three subsystems are shown in Fig. 1. Apparently, this system is structured from the point of view of the ship operator which means navigator.

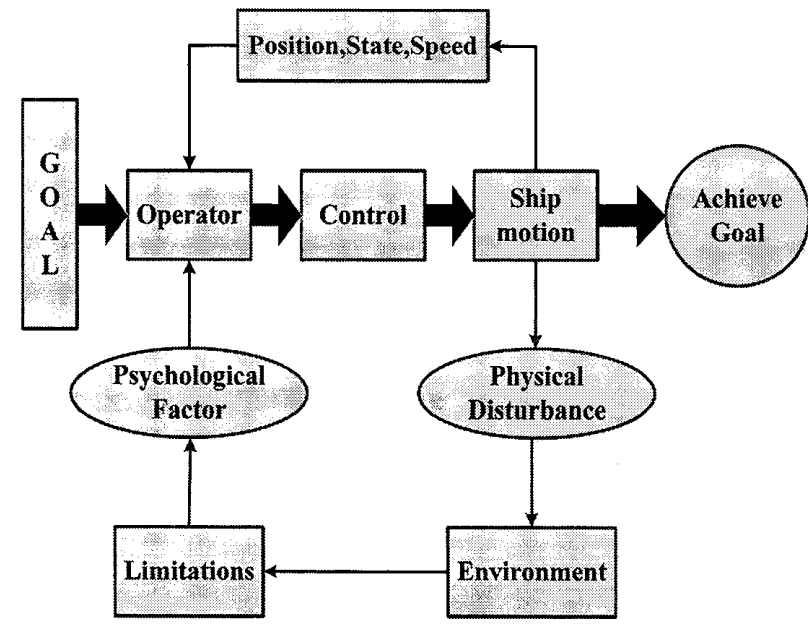

Fig.1 Relationship among operator, environment and ship ${ }^{[7]}$.

\subsection{Human Element in Maritime Transport Systems}

The maritime system is a people system (as shown in Fig.2). The technology interactions on people include perception, decision-making, and performance; the environment interconnections on people include physical and mental performance, fatigue, risk taking; the organization interconnections on people include fatigue, knowledge and skill, and work practices. In this system people (man) includes captain, navigator, ship's crew, pilots, dock-workers, VTS officer, operators and quarantine, customs and immigration officers. Technology (machine) is the interconnections on people include the design of the ship and the equipment of the ship that may have some kind of impact on people's performance and perception. Environment (media) means interconnections on people include weather environment, geographical, physical work environment and the regulatory, economic climates. Organization is (management) interconnections on people include and includes crew organization, company policies and the regulatory governance. Each of these system structures has its own characteristics. Some of them cover a wider scope, but people, ship, and environment are common components that they share.

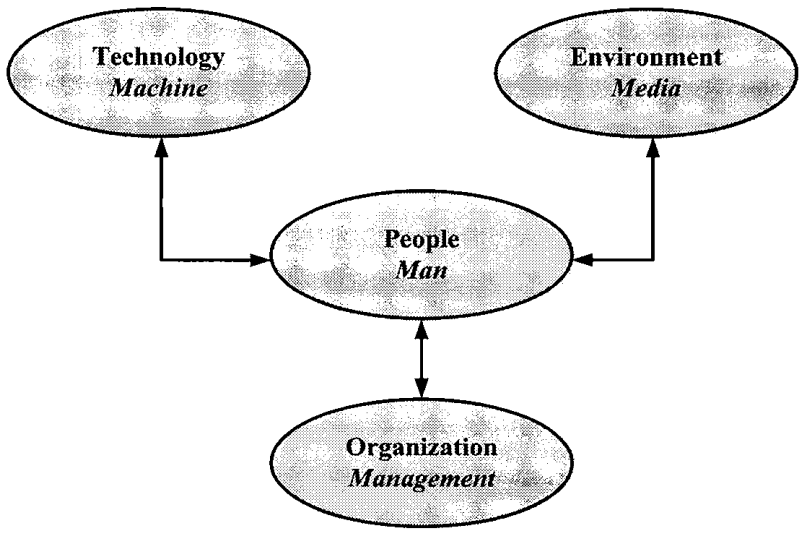

Fig.2 Development of model interconnections between technology, people, organization and environment in Maritime Transport System ${ }^{[8]}$.

\subsection{Methods of Quantitative Model}

Many models such as the Swiss cheese analogy model (Reason, 1997), the Bowtie model (Hollnagel,2008), the FSA (Formal Safety Assessment) (IMO, 2002), FTA (Fault Tree Analysis) and ETA (Event Tree Analysis) techniques, and other models have been introduced or proposed by experts in the fields with no reference to or systematic analysis of empirical data. Accident studies in many domains, including the maritime industry, are firmly rooted in qualitative methods and other summary statistics. The studies are largely confined to a few variables, such as vessel type, and business line, total loss incidents and some categories of accidents such as fire, explosion, collision, and grounding.

The development of statistical methods in a simple and sequential way would be helpful to explain and predict phenomena in the accident to the specific problems that are used when the database is also complete. Measures for risk minimization, such as the qualitative method, which evaluated with respect to 
their performance relation between man, machine, media and management is still very rarely used. Concept based on 4M (Man, Machine, Media and Management) factors.

Whereas incident or accident can be prevented when we can maintain the relationship of each element in maritime transport systems.

\section{Construction Estimating Causes of Collision Frequency}

The focus of this paper is to construct a classification framework for identifying and characterizing human elements involved in collisions at sea. For this purpose, various human element classifications used in different accident reports and databases will be reviewed. Within the MAIA (Marine Transport Inquiry Agency), Japan the data reports are classified under two kinds: accidents, and causes of accidents, at sea.

For these kinds of accidents, the item "collision" under accidents at sea, has the highest percentage of all.

The report shows causes of accidents which are most influenced by the human element.

\subsection{The Total Number Causes of Collision}

The essential attributes and relationships of the variables in the MAIA, Japan database were thoroughly studied. The database contains 29 variables representing the maritime systems and risk elements in complex relationships (see in Table 1).

The total number of variables are taken into consideration and from these data will be designed the new model equation. As the variable 'event description' was in text format it was excluded, as in that form, neither summary nor inferential statistics were applicable to it. However, the detailed information on marine accidents that it contained provided valuable insights for conceptual and relation analysis.

In view of the data provided by the report of MAIA, Japan the author has tried to make a simple equation that can ultimately be used to deduce the total number of each variable on the causes of the accident collision in the maritime transport systems.

This equation is

Total number of each causes $\left(\mathrm{Xi}^{\mathrm{i}}\right)=\sum_{\mathrm{j}}^{\mathrm{n}} \mathrm{F}($ Event $)$

Table 1 Causes of collision with Variable X1-X29.

\begin{tabular}{|c|c|c|c|}
\hline Related human element & Variable & Related human element & Variable \\
\hline Improper management & $\mathrm{X} 1$ & Improper ship's speed & $\mathbf{X 1 6}$ \\
\hline Poor repair condition & $\times 2$ & Not obeying COLREG & $\mathbf{X 1 7}$ \\
\hline Poor preparation for sea & $\mathrm{X} 3$ & Main engine failure & $\mathbf{X 1 8}$ \\
\hline Improper hydrographic survey & $\mathrm{X} 4$ & Auxiliary engine failure & $\times 19$ \\
\hline Poor selection and keeping & $\mathrm{X} 5$ & Poor management of lubricant oil & $\times 20$ \\
\hline Improper ship handling & $\mathrm{X} 6$ & $\begin{array}{l}\text { Poor management of electrical } \\
\text { equipment }\end{array}$ & $\mathrm{X} 21$ \\
\hline Unconfirmed ship's position & $\times 7$ & Improper handling and other task & $\times 22$ \\
\hline Improper look-out & $\mathbf{X 8}$ & Improper fishing work & $\mathrm{X} 23$ \\
\hline Snooze & $\mathbf{X 9}$ & Poor management of cargo loading & $\times 24$ \\
\hline $\begin{array}{l}\text { Insuffient maintenance of steering systems } \\
\text { and nautical instruments }\end{array}$ & $\times 10$ & Inadequate supervision & $\times 25$ \\
\hline $\begin{array}{l}\text { Poor attention of the meteorology and } \\
\text { oceanography }\end{array}$ & $X 11$ & Taking over the watch & $\times 26$ \\
\hline Improper anchoring and mooring & $\mathrm{X} 12$ & Poor management on fire & $\times 27$ \\
\hline Inadequate preparation for rough sea & $X 13$ & Force majeure & $\times 28$ \\
\hline $\begin{array}{l}\text { No indication of navigation lights and } \\
\text { shapes }\end{array}$ & $\mathbf{X 1 4}$ & \multirow[t]{2}{*}{ Others } & \multirow[t]{2}{*}{$\times 29$} \\
\hline Signalling failure & $\mathbf{x 1 5}$ & & \\
\hline
\end{tabular}

(Remarks: Bold fonts means remarkable and higher number of causes) 
Whereas the total number of each variable on the causes of the accident collision (Xi) which counted of F: frequency each event, where the event is sum of product during $n$ years; $\mathrm{j}$ : start and $\mathrm{n}$ : end of events have occurred; by using the equation 1 , it can be shown in Table 2 the frequency of collision causing an accident that occurred over an eleven-year period.

Table 2 Total number of causes of collision in period 1998-2008 variable X1-X29.

\begin{tabular}{|c|c|c|c|c|c|c|c|c|c|c|c|c|}
\hline \multirow{2}{*}{\begin{tabular}{|c|}
$\begin{array}{c}\text { Causes of } \\
\text { collision }\end{array}$ \\
$\begin{array}{c}\text { Related human } \\
\text { element Variable }\end{array}$ \\
\end{tabular}} & \multicolumn{11}{|c|}{ Frequency in each year } & \multirow{2}{*}{$\begin{array}{l}\text { Total of } \\
\text { number } \\
\text { causes }\end{array}$} \\
\hline & 1998 & 1999 & 2000 & 2001 & 2002 & 2003 & 2004 & 2005 & 2006 & 2007 & 2008 & \\
\hline $\mathrm{X} 1$ & 5 & 8 & 3 & 2 & 5 & 4 & 4 & 8 & 1 & 14 & 12 & 66 \\
\hline $\mathrm{X} 2$ & 1 & 0 & 0 & 0 & 0 & 1 & 3 & 1 & 1 & 5 & 3 & 15 \\
\hline $\mathrm{X} 3$ & 0 & 0 & 0 & 0 & 0 & 1 & 5 & 3 & 0 & 0 & 0 & 9 \\
\hline $\mathrm{X} 4$ & 1 & 4 & 5 & 3 & 4 & 5 & 3 & 1 & 6 & 3 & 4 & 39 \\
\hline $\mathrm{X} 5$ & 3 & 2 & 6 & 6 & 11 & 4 & 7 & 5 & 8 & 5 & 10 & 67 \\
\hline $\mathrm{X} 6$ & 21 & 24 & 22 & 15 & 21 & 21 & 11 & 14 & 18 & 21 & 11 & 199 \\
\hline $\mathrm{X7}$ & 13 & 10 & 17 & 17 & 8 & 9 & 11 & 9 & 16 & 9 & 8 & 127 \\
\hline $\mathbf{X 8}$ & 441 & 415 & 444 & 457 & 504 & 502 & 417 & 398 & 360 & 358 & 389 & 4685 \\
\hline $\mathbf{X 9}$ & 28 & 31 & 34 & 36 & 38 & 40 & 26 & 36 & 32 & 30 & 39 & 370 \\
\hline $\mathrm{X} 10$ & 2 & 1 & 2 & 0 & 0 & 2 & 0 & 1 & 1 & 0 & 5 & 14 \\
\hline $\mathrm{X} 11$ & 5 & 9 & 7 & 6 & 10 & 4 & 0 & 8 & 2 & 6 & 5 & 62 \\
\hline $\mathrm{X} 12$ & 2 & 3 & 2 & 3 & 1 & 3 & 3 & 1 & 2 & 6 & 2 & 28 \\
\hline $\mathrm{X} 13$ & 0 & 0 & 0 & 2 & 0 & 0 & 1 & 0 & 2 & 3 & 1 & 9 \\
\hline $\mathrm{X} 14$ & 21 & 30 & 16 & 31 & 21 & 18 & 15 & 13 & 8 & 6 & 10 & 189 \\
\hline $\mathrm{X} 15$ & 90 & 89 & 100 & 72 & 83 & 86 & 79 & 99 & 66 & 68 & 63 & 895 \\
\hline$\times 16$ & 62 & 47 & 56 & 54 & 5 & 23 & 27 & 42 & 21 & 9 & 5 & 351 \\
\hline $\mathbf{X 1 7}$ & 178 & 194 & 178 & 148 & 164 & 180 & 142 & 150 & 119 & 115 & 115 & 1683 \\
\hline $\mathrm{X} 18$ & 1 & 1 & 1 & 2 & 1 & 1 & 0 & 2 & 0 & 0 & 1 & 10 \\
\hline $\mathrm{X} 19$ & 3 & 2 & 5 & 1 & 3 & 2 & 1 & 2 & 1 & 2 & 0 & 22 \\
\hline $\mathrm{X} 20$ & 0 & 0 & 0 & 0 & 0 & 0 & 0 & 1 & 1 & 0 & 3 & 5 \\
\hline $\mathrm{X} 21$ & 0 & 1 & 0 & 0 & 0 & 0 & 0 & 1 & 2 & 2 & 0 & 6 \\
\hline $\mathrm{X} 22$ & 0 & 0 & 2 & 1 & 0 & 0 & 0 & 1 & 1 & 1 & 1 & 7 \\
\hline $\mathrm{X} 23$ & 0 & 0 & 0 & 0 & 0 & 0 & 0 & 0 & 0 & 0 & 0 & 0 \\
\hline X24 & 0 & 0 & 0 & 0 & 0 & 0 & 0 & 0 & 0 & 1 & 1 & 2 \\
\hline X25 & 70 & 76 & 68 & 38 & 53 & 45 & 44 & 51 & 43 & 38 & 45 & 571 \\
\hline $\mathrm{X} 26$ & 37 & 38 & 26 & 28 & 20 & 17 & 20 & 25 & 18 & 20 & 14 & 263 \\
\hline X27 & 0 & 0 & 0 & 0 & 0 & 0 & 0 & 0 & 0 & 0 & 0 & 0 \\
\hline $\mathrm{X} 28$ & 1 & 0 & 0 & 0 & 0 & 0 & 0 & 0 & 0 & 0 & 0 & 1 \\
\hline X29 & 1 & 0 & 1 & 0 & 0 & 1 & 0 & 3 & 4 & 5 & 6 & 21 \\
\hline
\end{tabular}

(Remarks: Bold fonts means remarkable and higher number of causes)

\subsection{The Relationships 4M Factors in the Causes of Collision}

In mathematics, an element, or member, of a set is any one of the distinct objects that make up that set ${ }^{[9]}$. The relation "is an element of", also called set membership, is denoted by the signature $\in$. Writing is $\mathrm{X} \in \mathrm{A}$

means that "X is an element of $A$ ". Equivalent expressions are " $\mathrm{X}$ is a member of $\mathrm{A}$.

In this paper, the elements covered are four categories relating to the maritime transport system for the safety known as Man, Machine, Media, and Management. From equation (1) and (2) could be explained in relation to the maritime transport system as

$\mathrm{Xi} \in\{$ Man or Machine or Media or Management $\}$

The number of elements in a particular set is a property known as cardinality; informally this is the size of a set. In the above the cardinality of the set for every elements man, machine, media and management are determined from the total number each causes 
(Eq.1) and perspective of the causes of induction $4 \mathrm{M}$ factors $^{[8,10]}$.

Table 3 shows the next stage has been done by reconstructing the relationships from the total number of collision in the maritime transport systems, more detailed explanation in section 4 .

In condition:

Table 3 The relationships 4M Factors with causes of collision in extreme cases

\begin{tabular}{|c|c|c|c|c|c|}
\hline \multirow{2}{*}{$\begin{array}{c}\text { Variable } \\
\text { causes of } \\
\text { collision }\end{array}$} & \multirow{2}{*}{$\begin{array}{c}\text { Total } \\
\text { number } \\
\text { of causes }\end{array}$} & \multicolumn{4}{|c|}{ 4M Factors of maritime transport system } \\
\hline & & Man & Machine & Media & Management \\
\hline X8 & 4685 & 은 & $=0$ & - & $=$ \\
\hline $\mathbf{X 9}$ & 370 & - & & - & - \\
\hline X14 & 189 & - & 3. & • & 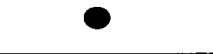 \\
\hline X15 & 895 & - & 0 & 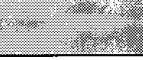 & 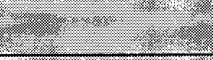 \\
\hline $\mathbf{X 1 6}$ & 351 & - & - & - & 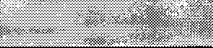 \\
\hline $\mathbf{X 1 7}$ & 1683 & - & $x^{2}-x^{2}$ & - & - \\
\hline $\mathbf{X 1 8}$ & 10 & - & - & $x$ & $\bullet$ \\
\hline $\mathbf{X} 25$ & 571 & 0 & $\sqrt{2}+5$ & (18) & - \\
\hline$\times 26$ & 263 & 0 & 1 & and & 0 \\
\hline
\end{tabular}

(Remarks: Bold fonts means remarkable and higher number of causes)

( $\square$ Not have relationships between causes of collision and one of $4 \mathrm{M}$ Factors)

( - Yes have relationships between causes of collisions and one of $4 \mathrm{M}$ Factors)

\section{Analysis of Related Causes of Collision in Maritime Transport System}

In analyzing the relationships of causes of collision in maritime transport systems (see in Table 3), perspective of the causes of induction $4 \mathrm{M}$ factors $^{[8,11,12]}$ arguments and simple equations (1),(2) have been used. Sources ${ }^{[11,12,13,14,15,16]}$ are from both printed theories and from opinions of experts, as well as from real accident reports.

Several explanations below are based on the greatest values of the total number that have been obtained in the calculation of Table 3 , and are as follows;

Improper look-out (X8). The international COLREGs define, under Rule 5, the criteria for keeping a proper look-out. Look-out is an important element of safe watch keeping, especially when the visibility is restricted and includes look-out by hearing, radar, VHF, AIS as well as by sight. There is no excuse for an improper look-out but there are frequently reasons: lack of support, low discipline, disinterest, carelessness, laziness to name but a few.
Snooze and fatigue (X9) could be due to how the motion of the ocean can affect one's balance, coordination, response time, eyesight, hearing, reflexes, judgment and the ability to enjoy daily work. The combination of wind and waves can cause sea sickness, which will affect motor skills and one's ability to think clearly. However, the main reasons are overwork, under-manning and non-adherence to the STCW Hours of Rest requirements. Operating a boat while fatigued is always a bad idea.

No indication of navigation lights and shapes (X14)" because a ship cannot suspend piloting operations when darkness falls and daytime navigational aids can no longer be seen. For purposes of identification, lights have individual characteristics regarding color, intensity, and system of operation. For this reason, aids to navigation are lighted whenever it is necessary. However, its application involves the exercise of special skills and fine techniques, which can be perfected only by experience and careful practice.

Signaling failures (X15). It refers to lack of proper 
interpretation about maneuver by the relevant signals on the ship's whistle. It further means any sound signaling appliance capable of producing the prescribed blasts and which comply with the specifications.

Improper ship's speed (X16). One of the factors affecting ship speed is correct operation of controllable pitch propellers. It is possible to operate under different conditions of displacement of ship resistance at the same engine RPM (Revolutions per Minute) and power by varying the pitch of the propeller. Operation of engines fitted with controllable pitch propellers should be in accordance with the applicable NAVSEA Technical Manual and Engineering Operating Sequencing System (EOSS) if applicable.

Not obeying COLREG (X17) can be put down to misinterpretation, even though the rules are quite clear. Ignorance on how to apply them in sea conditions, and plain, deliberate non-adherence when the situation may not be obviously understood, ensures that accidents, close-quarters situations and collisions do occur.

Generally item "main engine failure (X18)" because lack of overhauling a cylinder, means lack of a routine periodical maintenance task on a marine diesel engine to ensure that the components of that cylinder have not worn excessively and are fit to continue service. Management of preventative maintenance and inspection work is required to ensure that equipment is capable of operating as designed and to reduce the likelihood of failures in service.
Equipment manufacturers recommend service intervals and procedures for their equipment. If these are not observed, equipment can fail without warning.

Inadequate supervision of work on board (X25), where much equipment and systems are highly specialized, can lead to costly malfunctions. The vessel is only one element of a large project and a disciplined project management approach is required to ensure smooth dovetailing with the overall economics and design plan. Time or cost over runs can eliminate projected margins, making it critical that projects are completed on time with no compromise on cost or quality. Close supervision by qualified experts is therefore of critical importance, right from a vessel's inception on the drawing board, through its sea trials to final delivery.

Inadequate reporting and taking over the navigation, engineering or cargo watch (X26) is due to inadequate shipboard arrangements and managerial planning. The possibility of the officer of the watch being affected by fatigue caused by an excessive workload due to a watch system, which is possibly inadmissible for a vessel of this size and area of operation, as well as the course of the voyage, is excluded from plans.

Figure 3 describes the "relationships causes" of collision in the maritime transport systems. To complete this analysis graphically, the relationships between the causes of collision in the maritime transport system (man, machine, media and management) were reached by inserting the resultant values from the equation (1), (2) in the table 3.

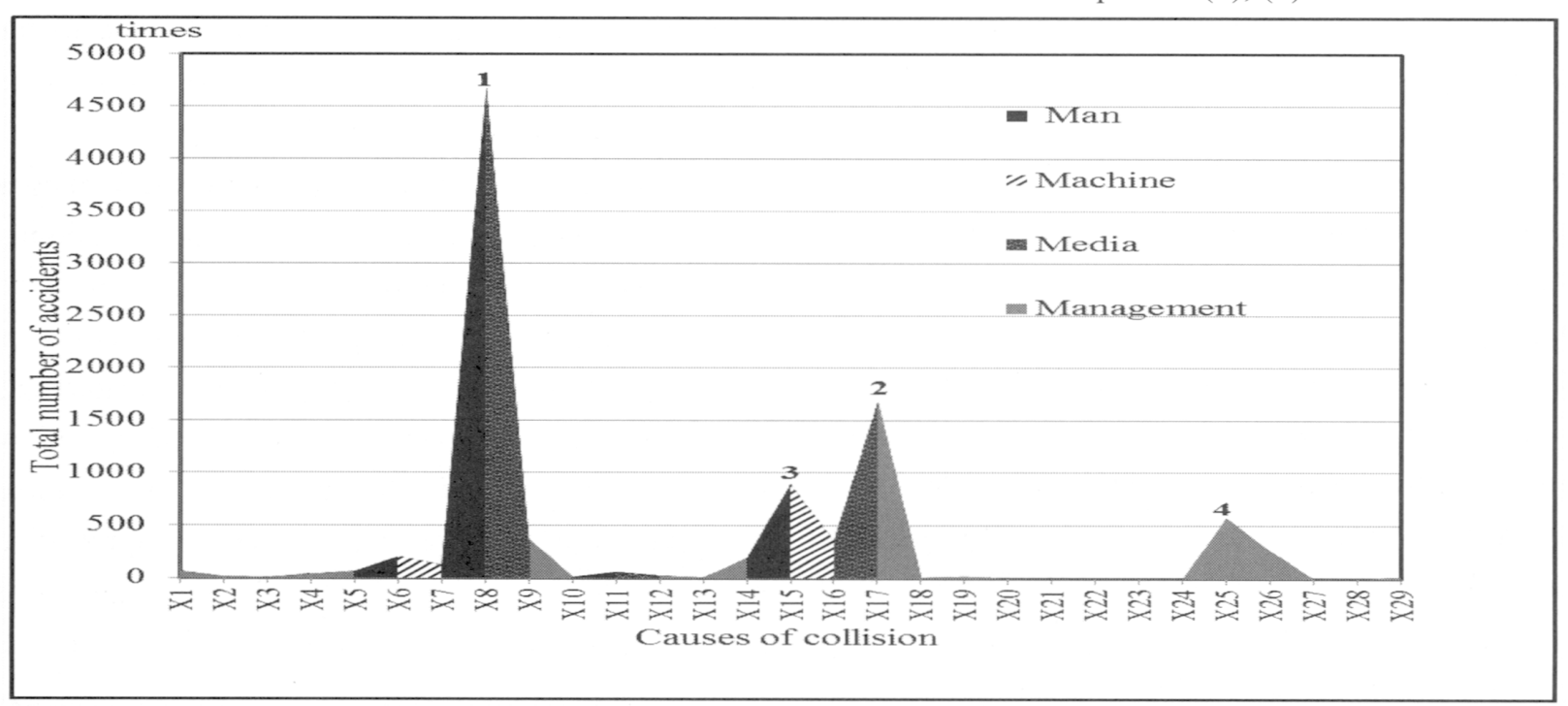

Fig. 3 The relationships causes of collision in the maritime transport system 


\section{Results}

Fig. 3 illustrates the highest influences of the relationships as causes of collision in the maritime transport system. All together the following results can be drawn:

(1) Relationships between man and media influenced by variable $\mathrm{X} 8$ (improper look-out), and $\mathrm{X} 9$ (snooze).

(2) Relationships between media and management influenced by variable X16 (improper ship's speed), X17 (not obeying COLREG) and X18 (main engine failure).

(3) Relationships between man and machine influenced by variable X14 (no indication of navigation light and shapes) and X15 (signaling failure).

(4) Relationships management influenced by variable X25 (inadequate supervision), and X26 (inadequate report).

\section{Considerations}

From the results that have been obtained, this paper argues that:

(1) Complicated Environment. The most significant relationship caused by collision accident on board, is the difficulty of fixing her position based on the complicated geographical and weather characteristics in Japan.

(2) Good Navigator. The good navigator should keep his/her ability for utilizing and controlling navigation equipment for the purpose of preventing incidents and accidents.

(3) Effective nautical equipment. The Automatic Identification System (AIS) is a great tool which can detect a larger number of targets, without considering shadow effect which can prevent a proper look-out. AIS also provides more voyage information for the VTS centers.

(4) Management arrangement.

Conducting the investigation of any accident takes a long time and consideration of conducting reports in real time will be effective.

(5) Attention and situation awareness.

The watch rotation and fatigue of the officers on board should be understood. Measures to call other officers when required should be in place so that exhausted officers do not have to take the watch and many accidents can be prevented.

\section{Conclusions}

In this matter, we strongly believe that:

(1) Reasonable to apply.

Using this qualitative model, we could find relationship causes of collision in the term maritime transport system.

(2) Flexible data.

Using one variable as independent we could find relationships to other data. Probabilistic arguments and logic have been used. Sources are from both printed theories and from opinions of experts, as well as from real accident reports.

(3) Alternative qualitative model.

Use of this model can be included as a second opinion in the decision-making for management improvement.

(4) Simulate qualitative model.

Using this model for the relations between man, machine, media and management in the maritime transport system for further research.

\section{Acknowledgement}

We would like to express special thanks to Captain Peter Pratley for his kind help and full support during the phases of this paper.

\section{References}

(1) Marine Accident Inquiring Agency of Japan: Statistics of accidents 1998-2008.

(2) Marine Accident Investigation Branch, U.K.: MAIB Annual reports 1991. London, Author, 2000.

(3) UK P\&I Club: Ten-year trends in maritime risk analysis of major claims a digest, London, Author 1999.

(4) Grime, R.P, J. Zhao, P.A. Wilson, Z. Hu \& F. Wang: Human factors, In Proceedings of the international conference on preventing collision at sea, Maritime collision and prevention Vol.1 pp314-329. Epson, Surrey Chiavari Publishing. 1996.

(5) Liu Zhejiang.: Identifying and reducing the involvement of human element in collision at sea, World Maritime University, Malmö, Sweden, 2001.

(6) International Maritime Organization.: Human element vision, principles and goals for the 
organization(Resolutions A.850(20)), London, Author, 1997.

(7) Gu, W. et al.: Safety of marine transportation, Dalian Maritime University Publishing House, 1993.

(8) Rothblum,A.M.: Human error and marine safety. World Wide Web: http:/www.uscg.mil/hq/g\%2Dm/risk/e\%2Dguid elines/html/vol4/volum.../humanerr.htm, 1996.

(9) Eric Schechter (1997): Handbook of Analysis and Its Foundations. Academic Press. ISBN 0-12-622760-8.

p.

12 ,

or

http://en.wikipedia.org/wiki/Element (mathemati cs)\#Sets

(10) FAA System Safety Handbook: Chapter 15: Operational Risk Management December 30, 2000.

(11) Steven Kristiansen: Maritime Transportation Safety Management and Risk Analysis, Elsevier Butterworth-Heinemann, Oxford, 2005.

(12) Ge Wang, John Spencer, Yongjun Chen: Assessment of a ship's performance in accidents, Marine Structures 15 access in www.elsivier.com/locate/marstruc, 2002.

(13) Thomas Koester: Human Factors and everyday Routine in the maritime work domain, http://imv.au.dk/ pba/Preprints/HumFact.pdf, 2011.

(14) Vladimir M. Trbojevic, Barry J. Carr: Risk based methodology for safety improvements in ports, Journal of Hazardous Materials 71 pp. 467-480, 2000.

(15) Haryanti Rivai, Masao Furusho, Shoji Fujimoto, Masaki Fuchi: Model of Human Elements for Maintenance Engineer on Maritime Field, IAMU 11 Conference Gydnia, Poland., 2010.

(16) Haryanti Rivai, Masaki Fuchi, Shoji Fujimoto, Masao Furusho, Analysis on Navigation Failures Being Causal to Maritime Disasters, ANC Wuhan,China,2011.

(17) Convention on the International Regulations for Preventing Collisions at Sea (COLREGs), 1972.

(18) Tatsuya Gamou, Hiroyuki Maruyama, Makoto Misayaka: A Guide to ship handling theory, The Best seamanship, Japan 2009.

(19) Bin Lin and Chih-Hao Huang, Comparison between ARPA Radar and AIS Characteristics for Vessel Traffic Services, Journal of Marine Science and Technology, Vol. 14, No. 3, pp. 182-189, 2006 .

\section{Questions and Answers}

Mr. El-Hocine TASSEDA (Tokyo University of Marine Science and Technology):

1. Is it order of $4 \mathrm{M}$ model relevant or not?

2. What does mean of "media" of the context of this paper?

\section{Haryanti RIVAI:}

1. The concept 4M (Man, Media, Machine, and Management) is not relevant based on the order. This method utilizes the concept of the method accident investigation used by the National Transportation Safety Board (NTSB) and rather than constituting mere guidelines on procedures.

2. Media is not newspaper or magazine. Media means environment. All aspect from environment interconnections on people includes weather environment, geographical, physical work environment and the regulatory, economic climates. 